\title{
HISTORIA DE LOS BOVINOS EN PANAMÁ Y SU RELACIÓN CON LAS POBLACIONES BOVINAS DE IBEROAMÉRICA
}

\author{
HISTORY OF PANAMA BOVINES AND THEIR RELATIONSHIPS WITHOTHER \\ IBEROAMERICAN POPULATIONS
}

\author{
Villalobos-Cortés, A. I.A1 , A.M. Martínez y J.V. Delgado ${ }^{\mathrm{B1}}$
}

1Departamento de Genética. Universidad de Córdoba. Ed. C-5. Campus de Rabanales. 14071 Córdoba. España.Az62vicoa@uco.es; Bid1debej@uco.es

\section{Palabras clave adicionales}

Razas criollas. Conservación. Recursos zoogenéticos.

\section{RESUMEN}

Se hace una revisión histórica sobre el origen de la ganadería en América; se describen las migraciones de bovinos que se realizan desde España hacia las islas y los primeros envíos de animales desde La Española y Santiago hacia tierra firme, como Santa Marta, Colombia; Tamaulipas, México y Santa María La Antigua, Panamá. Se relata el movimiento de animales por todo el territorio panameño, influenciado por la presencia de Pedrarias Dávila como Gobernador de Castilla del Oro y posteriormente como Gobernador de Nicaragua; se plantea la importancia del paso de bovinos por Panamá y su importancia en la conquista del Perú y Ecuador. Y se concluye con la hipótesis histórica de la influencia genética de los bovinos llegados al Nuevo Mundo sobre el territorio Iberoamericano particularmente los bovinos que llegaron a Panamá.

\section{SUMMARY}

An historic review of the origin of the American livestock is made; a description of the bovine migrations from Spain to the islands and the first sending of animals from La Española and Santiago to continental lands, like Santa Marta, Colombia; Tamaulipas, México and Santa María La Antigua, Panamá. The movement of animals over the Panamanian territory is related as influenced by Pedrarias Dávila, Governor of Castilla del Oro, later Governor of Nicaragua. The importance of

\section{AdDitiOnAL KEYWORDS}

Creole breeds. Conservation. Zoogenetic resources.

Panama like pathway of animals in the conquests of Peru and Ecuador is proposed. The historical hypothesis of the genetic influence of bovines arrived to the New World over the Iberoamerican territory, particularly the bovines of Panama is concluded.

\section{INTRODUCCIÓN}

El ganado Criollo se identifica con animales que se han reproducido y adaptado a una determinada región agroclimática, por un determinado periodo de tiempo (Giovambattista et al., 2001). Tal es el caso del ganado Criollo en América.

Los bovinos Criollos americanos (Bos taurus) procedentes de España, descendían directamente del Aurochs salvaje (Bos primigenius), domesticado durante la revolución agrícola en el periodo neolítico (Rouse, 1977; Beja-Pereira et al., 2006). Datos arqueológicos recientes sugieren que este proceso de domesticación fue muy complejo y de origen múltiple con introgresión de genes (por lo menos en algunas regiones) de razas locales y africanas, introducidas por vía marítima, por lo que les ha dado una importante variabilidad genética, particularmente a las razas del sur de Europa 


\section{VILLALOBOS-CORTÉS, MARTÍNEZY DELGADO}

(Beja-Pereira et al., 2006).

Se le adjudicaba a la ciudad de Sevilla la exclusividad para organizar los embarques oficiales a América. Hay autores que afirman que también salieron barcos desde Galicia en el norte de España (Primo, 1992; Postiglioni et al., 2002). Sin embargo no se conoce con certeza si todo el ganado provenía de las regiones cercanas a Sevilla o si los embarques se hicieron en las Islas Canarias, ruta y escala habitual en los viajes a América.

Algunos trabajos realizados indican que las razas españolas actuales podrían ser descendientes de los mismos planteles de los cuales provienen los Criollos, son: Retinta, Berrenda, Cacereña y Andaluza negra (Rouse, 1977; Bedoya, 2001).

El presente trabajo tiene como objetivo revisar la historia de los bovinos en la República de Panamá y su distribución sobre el territorio nacional y la influencia del mismo sobre el continente.

\section{LLEGADA DE BOVINOS A LA ESPAÑOLA}

Cuando Cristóbal Colón llegó a América en el año de 1492, no existían en el nuevo continente, animales domésticos, tales como: bovinos, ovejas, cerdos, gallinas, a excepción del perro (Martínez et al., 2000; Bedoya, 2001).

El primer embarque de un vacuno (Bos taurus) hacia el Nuevo Mundo se remonta al segundo viaje de Colón en 1493 desde la isla de La Gomera en las Islas Canarias (Primo, 1992; Rodero, 1992; Beteta Ortiz, 1997; Martínez et al., 2000; Tejera y Capote, 2005). Estos embarques se hicieron desde el principio por Sevilla, también desde las islas Canarias y tenían como destino la Isla de Santo Domingo llamada por Colón, La Española. En el tercer viaje vino un mayor número de animales vacunos, los cuales llegaron a la Isla de Santo Domingo que llegó a ser el punto de partida para la distribución de ganado hacia las Antillas y al Nuevo Con- tinente (Pinzón M., 1991). Sin embargo, de manera oficial, es en el tercer viaje del almirante, en el año de 1497, cuado se produce el envío de bovinos como se refleja en la Real Cédula de los Reyes Católicos, expedida en Medina del Campo sobre el envío de animales vacunos hacia el nuevo mundo. Beteta (1997) hace referencia a la forma detallada en que se describen en este documento las 40 yeguas que son enviadas en la expedición y por el contrario a los vacunos no se hace referencia sino de manera escueta, yunta de vacas coloradas e yeguas $e$ asnos con que labrar.

Esta última expansión ganadera fue bastante lenta pues los religiosos como Diego Colón, Gobernador de la Nueva España, habían prohibido la salida de bovinos para evitar la disminución del número de animales en la Isla por el excesivo traslado de ejemplares a otras islas y a tierra firme. Ante tal medida, la importación oficial de ganado a otros lugares del nuevo continente se produce treinta años después del segundo viaje de Colón. Existen diversos autores en diferentes países que reportan la llegada de los bovinos por diversas rutas y fechas desde España (Beteta, 1997; Guevara y LiraNoriega, 2006).

\section{LA GOMERA, PUNTO CLAVE DE ADAPTACIÓN}

Es importante destacar que al inicio de la época de la colonización de América, la participación de las islas Canarias, fue fundamental, particularmente la isla de la Gomera (Fray Bartolomé de las Casas, 1875; Don Fernando Colón, 1892; Tejera and Capote, 2005).

$\mathrm{Si}$ se consideran las condiciones de humedad, temperatura, alimentación y las cuatro estaciones del clima europeo y las comparamos con las condiciones de la región caribeña y mesoamericana, que es netamente tropical, a donde se desplazó en un principio al ganado, cabe preguntarse, cómo lograron una adaptación tan rápida. 
Es claro que al tener que reabastecerse los españoles en las islas Canarias y estar éstas influenciadas por el clima tropical africano, sirvieron como un punto de adaptación y abastecimiento intermedio de animales y plantas entre la Europa de cuatro estaciones y la América tropical. Los diversos animales que se llevaron a las Antillas y más fueron: cabras antiguas de Canarias, ovejas de pelo y carneros sin cuernos, cerdos negros de grandes colmillos, vacas de pequeño tamaño, gallinas que habían sido introducidas en Canarias por los europeos a mediados del XIV (Tejera y Capote, 2005). En la Historia de Indias de Fray Bartolomé de las Casas, se afirma la importancia de la Gomera en los primeros viajes de Colón ya que, según cuenta el historiador, de ahí se obtuvieron los alimentos para emprender el viaje hacia América. Fray Bartolomé describe así la llegada de Colón a la Gomera el 5 de Octubre de 1493: a 5 de Octubre, tomó la isla de la Gomera, donde estuvo 2 días, en los cuales se proveyó á mucha priesa de algunos ganados, que él, y los que venian, compraban, como becerras, y cabras, y ovejas; y entre otros, ciertos de los que venian allí compraron ocho puercas á 70 maravedís la piezas. Destas ocho puercas se han multiplicado todos los puercos que, hasta hoy, ha habido y hay en todas estas Indias que han sido y son infinitos; metieron gallinas también, y esta fué la simiente de donde, todo lo que hoy hay acá de las cosas de Castilla, ha salido lo mismo de las pepitas y simientes de naranjas, limones y cidras, melones y de toda hortaliza; proveyerónse de agua, y leña, y refrescos para toda el armada.

\section{TRASLADO A TIERRAS CONTINENTALES}

Algunos autores como Bedoya (2001) haciendo referencia a un trabajo de Pinzón (1984) sostienen que el primer traslado de animales a tierra firme fue en Santa Marta,
Colombia en Julio de 1525 por Rodrigo de Bastidas. Posteriormente Quiroz (2007) reporta que la introducción de bovinos a tierra firme la inició el mismo Bastidas, autorizado por una cédula real concedida el 16 de mayo de 1524 a llevar 200 vacas y otros animales domésticos a Santa Marta en Castilla de Oro (Colombia) desembarcando su carga el 29 de julio de 1524. Beteta (1999) y Romero (2006) hacen la misma afirmación sobre los bovinos en América, pero la fecha de desembarco la sitúan el 29 de Julio de 1525 . En el Archivo General de Indias (1525), la fecha que se observa es el 19 de Mayo 1525 (Toledo), Real Cédula al presidente y oidores de la Audiencia de la Española para que permitan sacar de la isla, ganados, vacas, cabras, ovejas y puercos para llevarlos a tierra firme. Por lo que consideramos que la fecha de salida para Santa Marta, de Rodrigo de Bastidas no debe ser anterior al 19 de Mayo de 1525 y su desembarco en Santa Marta sería efectivamente el 29 de Julio de 1525.

Otros historiadores hacen referencia a una fecha anterior para la llegada de bovinos: el año 1521. Así se observan dos referencias relativas a desembarcos de bovinos en dos sitios diferentes. Una hace alusión a Gregorio de Villalobos, colaborador de Hernán Cortés durante la conquista de México, quién desembarcó 50 cabezas de ganado en el río Panuco, en un valle cercano a lo que en la actualidad es Tampico, Estado de Tamaulipas (Dary, 1989; Ulloa-Arvizú, 2007). La otra referencia es la que reportan Castro (2006) y Cortés (2002) de una solicitud de Pedrarias Dávila, fundador de la ciudad de Panamá y conquistador del istmo, de importar cincuenta reses desde las haciendas que poseía en la isla de Santiago (Jamaica). Esta segunda referencia pudo ser corroborada a través del Archivo General de Indias, donde aparecen, cédulas reales que en primera instancia, ordenaban que se enviara a Panamá, ganado y otros artículos para los pobladores de la Ciudad de Panamá en Castilla del Oro. 


\section{VILLALOBOS-CORTÉS, MARTÍNEZY DELGADO}

La primera Cédula que se observa sobre el tema de envíos de animales a Panamá es la de Burgos el 6 de Septiembre de 1521 Real Cédula a la ciudad e Panamá, comunicándole la victoria sobre el movimiento comunero de Castilla y sobre los franceses de Navarra; que se han visto los memoriales que enviaron con sus procuradores Francisco de Lizaur y Benito Hurtado y sobre ellos se ha mandado dar las mercedes y libertades que verán por las provisiones que remite; que aunen sus esfuerzos con el Gobernador de Castilla del Oro para descubrir por la Mar del Sur; que den a sus procuradores los maravedies que tenían asignados a Pedrarias Dávila para venir a la corte; que para remediar la escasez de bastimentos se ha mandado a Francisco de Garay; gobernador de la isla de Santiago que ponga a su disposición cincuenta vacas, cincuenta becerras, doscientas ovejas, mil cerdos y dos mil cargas de cazabe para repartir entre los vecinos. La segunda referencia que se observa en el archivo general, correspondiente a envíos de animales a Panamá es la de Vitoria el 18 de Enero de 1522; Real Cédula a los oficiales de la Isla de Santiago para que guarden y cumplan como si a ellos fuese dirigida, la cédula que se envió a Francisco de Garay, poblador de dicha isla, referente a que diese de las granjerías y haciendas reales ciertos ganados y pan cazabi y los vecinos y pobladores de la ciudad de Panamá en Castilla del Oro (Archivo General de Indias, 1522). La tercera referencia de envíos de ganado aparece en el Archivo General de Indias en Medina del Campo el 4 de noviembre de 1531; Real Cédula a los oficiales reales de Jamaica, a petición de la ciudad de Panamá, para que entreguen a dicha ciudad ganado y pan cazabe en cumplimiento de la Real Cédula de 6 de Septiembre de 1521 -que se inserta-por la que se mandó a Francisco de Garay, capitán de dicha isla, que de las granjerías y ganados que S.M. tenía en ella entregase a la nueva ciudad de Panamá cincuenta becerras y vacas, mil cabezas de puercos, doscientas ovejas y dos mil cargas de pan cazabe, para repartir entre los vecinos y favorecer el poblamiento de la ciudad (Archivo General de Indias, 1531). La introducción de poblaciones de animales totalmente nuevas por parte de España, en Panamá, significó evidentemente un nuevo efecto sobre el ambiente. Los conquistadores se dieron la tarea de ejercer la influencia de sus costumbres traídas de su vida cotidiana sobre el nuevo ecosistema, pero el comportamiento de las nuevas especies no fue problema debido a que como se ha comentado anteriormente el papel de la Gomera en el proceso de adaptación de los animales fue fundamental dado que los climas de las regiones indianas y el de cuatro estaciones de Europa, no guardaban ninguna relación. Parte del germoplasma importado de Europa como el trigo, la vid y la oliva no se adaptó al trópico hostil, pero si lo lograron el arroz, el café, la caña de azúcar, el limón y la naranja. Además, cabe destacar la sorprendente adaptación de las especies de bovinos, caprinos, ovinos, suinos, y gallinas al nuevo mundo (Cortés, 2002).

\section{DISTRIBUCIÓN DE BOVINOS ENEL TERRITORIOPANAMEÑO}

La ganadería en el istmo se remonta al menos al año de 1521, cuando la corona española accedió a la solicitud de Pedrarias Dávila, fundador de la Ciudad de Panamá y Gobernador de Castilla del Oro, de importar cincuenta reses y otros bastimentos desde la isla de Santiago (Archivo General de Indias, 1521). Estos animales ingresaron vía Darién, donde no lograron una buena adaptación pero se reprodujo muy bien en las ciudades de Panamá, Natá y en Remedios y llegando a tener una importante presencia desde lo que es hoy la provincia costarricense de Guanacaste hasta Chiapas y hacia el sur en Perú (Cortés, 2002; Castro, 2006). Es posible que la influencia de Pedrarias Dávila haya sido determinante en el movi- 
miento de estos animales en la región centroamericana, pues fue él mismo quien trajo éstos a Panamá y al ser nombrado Gobernador de Nicaragua ha promovido la cría de ganado.

No se tiene información tan detallada sobre la ganadería en la Audiencia de Guatemala pero sí hay alguna mención de este ganado en muchas de las relaciones de la época colonial. Tal es el caso de Fray Alonso Ponce en la crónica de su viaje en el año 1586, donde menciona la existencia de ganado mayor en Guatemala, San Salvador, Honduras, Nicaragua y Costa Rica (HeckadonMoreno, 1997; Cortés, 2002).

\section{LA CRISIS GANADERA Y SU EFECTO SOBRE LA POBLACIÓN DE BOVINOS EN PANAMÁ}

La ganadería en Panamá logra gran prosperidad al punto de que para fines del siglo XVI la población de bovinos alcanza unos 150000 animales entre las ciudades de Natá y Panamá (Cortés, 2002). Este valor va descendiendo debido a la crisis minera que ocurre en Veragua en el año 1589, cuando colapsa el Real de minas de Concepción, que era un centro de desarrollo de gran importancia para la región central y que se mantenía independiente económicamente de la región de tránsito en Panamá. Esta región se abastecía de la carne proveniente de Natá y Los Santos y al desaparecer este asiento minero, la población se desplaza a otras regiones como la de Santa Fé y otras ciudades pequeñas como Remedios, Montijo y Alanje, provocando tensiones entre la ciudad y el campo (Torres, 1981). Este choque se lleva a efecto por la presión de los productores de Natá y Los Santos al colocar su carne en el mercado de la ciudad de Panamá y Nombre de Dios dónde ya existía autoabastecimiento de carne, gracias a unas 80000 cabezas de ganado que poseían por lo que no se hizo esperar la oposición de los aristócratas ganaderos quienes poseían el monopolio del abasteci- miento de carne de la gente que utilizaba al istmo como tránsito a Perú y de las exportaciones de ganado hacia esta región.

A pesar de los esfuerzos de los ganaderos de Natá y Los Santos para colocar su carne en el mercado citadino, después del colapso de la economía minera de Concepción, no lo lograron y paradójicamente la sobrepobla-ción ganadera y la posición de los productores de Panamá, precipitó el sistema productivo hacia una grave crisis acompañada del incremento en el precio de la carne: de real y medio, la arroba de carne de vaca pasó a costar dos reales y medio en las carnicerías de la ciudad; $y$, de tres reales la arroba de ternera pasó a cinco reales. Andrés Pérez de Salinas, que en ese momento era Procurador General de Panamá, presenta en un documento memorial en 1591, los detalles del problema. El documento hace referencia a que los ganaderos de la capital se ponen de acuerdo para monopolizar la producción y distribución del la carne bovina, comprando todos los hatos bovinos del distrito y parte del de Natá al punto que un miembro había comprado 14 hatos él solo. La estrategia era sacrificar una gran cantidad de reses de la ciudad de Panamá y Nombre de Dios para disminuir el tamaño de la cabaña y disparar los precios.

Por otro lado fue dictada una ordenanza que obstruía la venta de animales en la capital por parte de los vecinos de Natá y Los Santos lo que los llevó a vender sus animales a precios demasiado bajos. El documento también hace referencia a la llegada de barcos a Portobelo que, según las órdenes recibidas de la corona, debían pasar el invierno en Tierra Firme, provocando un incremento de la demanda de carne. Es probable que este haya sido el factor desencadenante del proceso iniciado deliberadamente por los ganaderos más ricos de la ciudad. El acaparamiento de los hatos supuso también la apropiación indebida de tierras comunales y el perjuicio de los pequeños ganaderos. 


\section{VILLALOBOS-CORTÉS, MARTÍNEZY DELGADO}

Toda esta situación fue causa de que se produjese en Natá y Los Santos un notable empobrecimiento de la ganadería y que en Panamá, donde había hasta hacía poco no menos de 80000 reses, en 1592 no quedasen más que 24000 (Torres, 1981; Jaén, 1981).

La crisis ganadera duró cerca de 17 años ya que Panamá, Natá y Los Santos no llegaban a reunir en conjunto más de 88000 cabezas de ganado en 1602. Todavía en el año de 1650 Natá no había logrado recuperar la población bovina que tenían entre los años de 1575 a 1592. El Obispo Hernando Ramírez, menciona que el número de cabezas era entonces de 50000, lo que representa 20000 animales menos, antes de la crisis minera (Torres, 1981).

Arturo Guzmán Navarro hace una referencia de la ganadería y plantea lo siguiente: en las márgenes del Caimito y más allá hacia Occidente, hasta Chame, se van desarrollando progresivamente haciendas ganaderas que son atendidas por negros esclavos, mientras sus propietarios residen en la ciudad de Panamá. Esto explica, por qué en los inicios de siglo XVII (1609) existían seis hatos con una totalidad de 4000 reses en la región caimiteña; en Perequeté, dos hatos con 3000 reses en Capira, dos hatos con 3000 reses y en Chame, de cuatro a seis hatos con 9500 reses (Guzmán Navarro, 2006). En ese mismo orden de ideas, Castillero, (1967) menciona que ese año (1609), en Alanje había 8 hatos que en conjunto, sumaban 9400 reses; Remedios contaba con 6 hatos y 7800 cabezas; en Montijo y Santa Fé había 9 hatos y 5900 cabezas. En toda la provincia de Veragua se contaban, con 23000 cabezas de ganado, cifra muy alta observandose que la mayoría de esos hatos se formaron a partir de 1589 . El desarrollo de la ganadería fue impresionante, en lo subsiguiente; sin embargo, ese progreso no se presentó en todas las regiones con la misma eficacia. Al final de siglo, la población ganadera de Remedios había decrecido, siendo entonces de sólo 4400 cabezas, esto es, poco más de la mitad de la existente en 1609. En cambio Alanje, no demoró en señalarse como zona ganadera por excelencia de la provincia; en 1650 la población bovina había ascendido a 20000 animales (Castillero, 1967).

Entre los años de 1690 y 1700 se efectúan las primeras adjudicaciones de títulos, más allá de de la región de Campana, al Oeste de la capital. Tres hatos ganaderos tendrán, así, tierras legalmente constituidas, como el caso de Rodrigo de Betancourt, comisario real y gran personaje de la sociedad del Istmo que era propietario en Los Llanos Del Chirú de 30000 hectáreas. En el territorio de Antón, el Corozo de 15000 ha, y cerca de Natá, una extensión no conocida (Jaén, 1981) Por ese tiempo, Antonio de Echevers y Subiza era considerado el más conspicuo de los terratenientes del Istmo, y era probablemente el hombre más rico e influyente en el Panamá colonial (Castro, 2003 y 2006). La población de bovinos logra una remontada cerca del año 1790 con una población vacuna de 83000 cabezas. En el año 1970 alcanza 1403440 y en la actualidad con 1,5 millones que se mantenia sin variaciones importantes diez años mas tarde (Jaén, 1981).

\section{MIGRACIONES HACIA EL PERÚ}

La ganadería en el Perú fue desarrollada con base en los animales llevados de Santo Domingo por los primeros colonizadores. Estos animales hacían su primera escala en Panamá para luego continuar hacía el Perú y el Ecuador. De esta forma Panamá, también se convirtió en el centro de acopio y distribución de bovinos para las colonias suramericanas. Documentos extraídos del Archivo General de Indias muestran algunas cédulas Reales donde se autoriza a diversos viajeros para el envío de animales hacia el Perú. Hay referencias en las que a los embarques, se les hacia exención del almojarifazgo a los propietarios de Panamá, mas no para los intermediarios cuyo propósito era la venta, como se aprecia en el siguiente texto: Real Cédula a los oficiales 
reales de la provincia del Perú, a petición de Toribio Montañés de Lara, en nombre de la ciudad de Panamá, para que de todas las crías de ganados que cada uno de los vecinos de la provincia de Tierra Firme lleve a la dicha provincia del Perú, siendo suyas propias, no le lleven derechos de almojarifazgo, pero si las llevare otra persona para venderlas o para otra cosa, no siendo suyas propias, ha de pagar los tales derechos (Archivo General de Indias, 1536). El 19 de diciembre de 1550 se expide otra Real Cédula para el traslado de animales hacia el Perú, bajo ciertas restricciones: Real Cédula a Sancho Clavijo, a petición de Sebastián Rodríguez, en nombre de Gómez de Tapia, vecino de Panamá, quien ha solicitado que se le permita enviar a Perú tres hombres que conduzcan y vendan sus ganados en dicha provincia. Que permita que vayan los que crea necesarios para la conducción de dicho ganado, siempre que no sean casados ni de los prohibidos (Archivo General de Indias, 1550). En el año de 1551 se encuentran dos cédulas reales, concedidas para el traslado de animales hacia el Perú: Real Cédula por la que se concede licencia a Juan Fernández de Rebolledo, vecino y regidor de Panamá, para pasar doscientas becerras al Perú (Archivo General de Indias, 1551a) y Real Cédula por la que se concede a Luis Suárez, vecino de Panamá, licencia para enviar doscientas terneras al Perú, sin que se le ponga impedimento alguno, siempre que no quede aquella tierra desabastecida (Archivo General de Indias, 1551b). De acuerdo con García (1984), la vocación ganadera de Pa-

\section{BIBLIOGRAFÍA}

Archivo General de Indias. 1521. Despacho para la ciudad de Panamá. Disponible en: Portal de Archivos Españoles. Sevilla. Panamá, 233, L.1, F.288V-290R. http://pares.mcu.es/. Fecha de acceso: 20/08/07.

Archivo General de Indias. 1522. Orden a los oficiales de la isla de Santiago. Disponible en: namá data de fechas muy tempranas. Aunque se desconoce el momento exacto en que se produjo el despegue de esta actividad, se supone que es a partir de 1530 , una vez superados los críticos momentos de la conquista del Perú. Los datos recabados sobre la vida de Pedrarias Dávila, sugieren que fue responsable de la influencia más grande y el gestor de esta actividad, aprovechando su cargo de Gobernador de Castilla del Oro y posteriormente, como Gobernador de Nicaragua, a lo largo del territorio Panameño y en el resto de Centroamérica.

\section{CONCLUSIÓN}

Finalmente haciendo una evaluación general del movimiento de animales y los datos aportados por el Archivo General de Indias otros historiadores persisten plantear la hipótesis histórica de que el bovino Criollo panameño es originario de la isla de Santiago (Jamaica) promovido por Pedro Arias de Ávila (Pedrarias) en 1521 y cuya influencia es ejercida por toda Centroamérica y parte de México en sus inicios. Que los mismos planteles de bovinos que llegaron a Panamá también tienen influencia sobre los bovinos criollos del área de Perú y Ecuador. Por otro lado, los bovinos Criollos de Colombia, Venezuelay en general de la Vertiente del Atlántico sur, se originaron de los planteles de bovinos traídos por Rodrigo de Bastidas en 1525, desde La Española (República Dominicana).

Se podría esperar que con las evaluaciones genéticas de las razas Criollas de iberoamérica pudiera ser demostrada esta hipótesis histórica.

Portal de Archivos Españoles. Sevilla. Indiferente, 420, L.8, F.357R-357V. http://pares. mcu.es/. Fecha de acceso: 20/08/07.

Archivo General de Indias. 1525. Que los de tierra firme saquen ganados de la Española. Disponible en: Portal de Archivos Españoles, Sevilla. Panamá, 233, L.2, F.57V-58R. http://pares. 


\section{VILLALOBOS-CORTÉS, MARTÍNEZY DELGADO}

mcu.es/. Fecha de acceso: 20/08/07.

Archivo General de Indias. 1531. Envío de mantenimientos de Jamaica a Panamá. Disponible en: Portal de Archivos Españoles, Sevilla. Panamá, 234, L.5, F.1V-3R. http://pares.mcu.es/. Fecha de acceso: 20/08/07.

Archivo General de Indias. 1536. Exención de almojarofazgo al ganado de Panamá. Disponible en: Portal de Archivos Españoles, Sevilla. Panamá, 235, L.6, F.66V-67R http://pares.mcu.es/. Fecha de acceso: 20/08/07.

Archivo General de Indias. 1550. Pase a Perú de tres empleados de Gómez de Tapia. Disponible en: Portal de Archivos Españoles. Sevilla. Panamá, 235, L.8, F.330V-331R. http://pares.mcu.es/ Fecha de acceso: 20/08/07.

Archivo General de Indias. 1551a. Licencia a Juan Fernández para pasar ganado al Perú. Disponible en: Portal de Archivos Españoles. Sevilla. Panamá, 236, L.9,F.8V-9R. http://pares.mcu.es/. Fecha de acceso: 20/08/07.

Archivo General de Indias. 1551b. Licencia a Luis Suarez, para enviar ganado al Perú. Disponible en: Portal de Archivos Españoles. Sevilla. Panamá, 236. L.9, F.19V-20R. http://pares.mcu.es/. Fecha de acceso: 20/08/07.

Beja-Pereria, A., D. Caramelli, C. Lalueza-Fox, C. Verensi, N. Ferrand, A. Casoli, F. Goyache, L. Royo, S. Conti, M. Lari, A. Martini, L. Ouragh, A. Magid, A. Atash, A. Zsolnai, P. Boscato, C. Triantaphylidis, K. Ploumi, L. Sineo, F. Mallegni, P. Tarbelet, G. Erhard, L. Sampietro, J. Bertrantpetit, G. Barbujani, G. Luikart and G. Bertorelle. 2006. The origin of European Cattle: Evidence from modern and ancient DNA. Proc. Natl. Acad. Sci. U.S.A., 103: 8113-8118.

Bedoya, G., L.Carvajal, N. Bermúdez, F. Moreno, M. Márquez, S. Davies, J. Derr, J. Ossa y A. Ruiz. 2001. Estructura molecular y poblacional del ganado Criollo Colombiano (GCC). Rev. Col. Cienc. Pec. 14: 107-118.

Beteta Ortiz, M. 1997. Las razas autóctonas españolas y su participación en los bovinos Criollos iberoamericanos. Simposium sobre utilización de razas y tipos bovinos creados y desarrollados en Latinoamérica y el Caribe. Maracaibo. Venezuela. 24-28 de noviembre. ALPA, XV Reunión.

Beteta, M. 1999. Llegada del vacuno español a Suramérica. Conferencia 15-12-1999. Real
Academia de Ciencias Veterinarias de España. Madrid.

Castillero, A. 1967. Estructuras sociales y económicas de Veraguas desde sus orígenes históricos, siglo XVI y XVII. Editora Panamá. Panamá. p. 93-94.

Castro, G. 2003. Panamá: agua y desarrollo en vísperas del segundo siglo. En: publicación seriada Tareas, Nro. 114, mayo-agosto 2003. Cela. Panamá. p. 21-52.

Castro, G. 2006. Panamá: agua y desarrollo en vísperas del segundo siglo. En: publicación seriada Tareas, Nro. 114, mayo-agosto 2003. Cela. Panamá. p. 21-52.

Cortés, R. 2002. Sociedad y naturaleza antes y despues de la conquista y colonización de América Central. Intercambio. Universidad de Costa Rica № 1. Mayo 2002.

Dary, D. 1989. Cowboy culture: A saga of five centuries. University of Kansas Press, Lawrence. Kansas.

Don Fernando Colón. 1892. Historia del Almirante Don Cristóbal Colón. Vol. 1, Madrid. Disponible en: Biblioteca Virtual Miguel de Cervantes. http://www.cervantesvirtual.com/FichaObra. $h$ html?Ref=21388\&portal=0. Fecha de acceso: $1 / 10 / 09$.

Fray Bartolomé de las Casas (ed.) 1875. Historia de las Indias. Vol. 2, pp. 1-3. Imprenta de Miguel Ginesta, Madrid. Disponible en: Biblioteca Virtual Miguel de Cervantes. http://www. cervantesvirtual.com/FichaObra.html?Ref= 21466\&portal=0. Fecha de acceso: 28/09/09.

Garcia, M.C. 1984. Quinto centenario del descubrimiento de América. La Sociedad de Panamá en el Siglo XXI. Editorial Artes Graficas Padura, S.A. Luis Montoto, 140. Sevilla. España. 25 p. Giovambattista, G., M.V. Ripoli, P. Peral-García, and J.L. Bouzat. 2001. Indigenous domestic breeds as reservoirs of genetic diversity: the Argentinean Creole cattle. Anim. Genet., 32: 240-247.

Guevara, S. and A. Lira-Noriega. 2006. De los pastos de la selva a la selva de los pastos: La introducción de la ganadería en México. Pastos, XXXIV: 109-150.

Guzmán Navarro, A. 2006. Orígenes históricos: de la Chorrera Castellana a la Chorrera Boliviana. Revista Cultural Lotería, № 460, mayojunio. República de Panamá. Panamá. 


\section{HISTORIA DE LOS BOVINOS EN PANAMÁ}

Heckadon-Moreno, S. 1997. Spanish rule, independence, and the modern colonization frontiers. In: Coates, A. (ed.). Central America: A natural and cultural history. Yale University Press. New Haven and London. p.177-214.

Jaén, O. 1981. Hombres y ecología en Panamá. Editorial Universitaria. Smithsonian Tropical Research Institute. Panamá. 157 p.

Martínez, R.D., E.N. Fernández, E.R. Género and F.J.L. Rumiano. 2000. El ganado bovino Criollo en Argentina. Arch. Zootec., 49: 353-361.

Pinzón, E. 1984. Origen de las razas bovinas criollas colombianas. Historia de la ganadería bovina en Colombia. Suplemento ganadero. Carta Ganadera. p. 55-103.

Pinzón, E. 1991. Cómo se originó la ganadería colonial colombiana. Suplemento Ganadero. Banco Ganadero, vol. 8: 34-36.

Postiglioni, G. R., L. Kelly, S. Llambi, G. Fernández, M. Dangelo, G. Gagliardi, J. Trujillo, M. de Bethencourt, K. Guevara, A. Castellano y M. Arruga. 2002. Biodiversidad genética de los bovinos Criollos del Uruguay. Análisis con marcadores moleculares. Arch. Zootec., 51: 195202.

Primo, A.T. 1992. El ganado bovino ibérico en las américas: 500 años después. Arch. Zootec., 41 (extra): 421-432.

Quiroz, V. 2007. Caracterización genética de los bovinos Criollos mexicanos y su relación con otras poblaciones bovinas. Tesis Doctoral. Universidad de Córdoba. Córdoba. España. 155 p.
Rodero, A., J.V. Delgado and E. Rodero. 1992. Primitive andalusian livestock and their implication in the discovery of América. Arch. Zootec. (extra): 383-400.

Romero, P. 2006. Movilidad social, educación y empleo: Los retos de la política económica del departamento del Magadalena. Banco de la República. Centro de Estudios Económicos Regionales (CEER). Cartagena de Indias. Colombia. № 74.

Rouse, J.F. 1977. The Criollo, spanish cattle in the Americas. Universíty of Oklahoma Press. Norman. p. 303

Tejera, G.A. y A.J. Capote. 2005. Colón y la Gomera. La colonización de la Isabela (República Dominicana) con animales y plantas canarias. Centro de Cultura Popular Canaria. Tenerife. España.

Torres, J. 1981. Desde la transformación del istmo en zona de tránsito hasta su sustitución, con el fin de las ferias de Portobelo y el sistema de flotas y galeones, por el sistema de barcos y registros sueltos por el Cabo de Hornos como principal ruta a Buenos Aires y Lima (15321739/48). Población economía y sociedad. Biblioteca de la Cultura Panameña. Tomo II. Universidad de Panamá. p. 265-300.

Ulloa-Arvizu, R., A. Gayosso-Vazquez, M. Ramos-Kuri, F.J. Estrada, M. Montaño and R.A. Alonso. 2008. Genetic analysis of Mexican Criollo cattle populations. J. Anim. Breed. Genet., 125: 351-359. 